\title{
A Retrospective Review of the Clinical Characteristics and Blood Glucose Data from Cellnovo System Users using Data Collected from the Cellnovo Online Platform
}

Olivia Hautier-Suply, Yasmin Friedmann and Julian Shapley

Cellnovo Ltd., Bridgend, UK

DOl: https://doi.org/10.17925/EE.2018.14.1.30

$\mathrm{T}$

echnological advances have led to innovative insulin delivery systems for patients with type 1 diabetes mellitus. In particular, the combination of miniature engineering and software algorithms contained in continuous subcutaneous insulin infusion (CSII) system pumps provide the user and the healthcare practitioner with an opportunity to review and adjust blood glucose (BG) levels according to system feedback, and to modify or programme their regimen according to their needs. While CSII pumps record a number of data parameters such as BG level, carbohydrate intake, activity and insulin delivered, these data are generally 'locked in' and can only be accessed by uploading to a cloud-based system, thus information is not contemporaneous. The Cellnovo Diabetes Management System (Cellnovo, Bridgend, UK) allows data to be transmitted securely and wirelessly in real time to a secure server, which is then retrieved by an online platform, the Cellnovo Online platform, enabling continuous access by the user and by clinicians. In this article, the authors describe a retrospective review of the patient data automatically uploaded to the Cellnovo Online platform. Baseline clinical and demographic characteristics collected at the start of pump therapy are shown for all patients, and BG data from a sub-cohort of patients who have been using the system for at least 6 months and who take and record an average of three BG level tests per day are presented to demonstrate glycaemic data over time.

\section{Keywords}

Diabetes management, online platform data, continuous

subcutaneous insulin infusion, HbA1C

Disclosure: Olivia Hautier-Suply, Yasmin Friedmann and

Julian Shapley are employees of Cellnovo Ltd.

Review Process: Double-blind peer review.

Acknowledgements: Medical writing support was provided by Deborah Glover, Independent Medical Editor, and Ray Ashton, Richmond Medical Communications. Compliance with Ethics: This study involves a retrospective review of the data and did not involve any studies with human or animal subjects performed by any of the authors. Written informed consent was obtained from the patients to the anonymous collection, storage and use of their demographic and clinical data.

Authorship: All named authors meet the International committee of

Medical Journal Editors (ICMJE) criteria for authorship of this manuscript, take responsibility for the integrity of the work as a whole, and have given final approval to the version to be published. All named authors contributed to the aim of the review, the retrieval and analysis of the data and the text.

Open Access: This article is published under the Creative Commons Attribution Noncommercial License, which permits any non-commercia use, distribution, adaptation and reproduction provided the original author(s) and source are given appropriate credit. (c) The Authors 2018.

Received: 5 December 2017

Accepted: 22 January 2018

Citation: European Endocrinology. 2018;14(1):30-34

Corresponding Author: Olivia Hautier-Suply, MD Medical Affairs

Manager, Cellnovo Ltd, Pencoed Business Park, A473, Pencoed,

Bridgend, CF35 5HZ, JK. E. olivia hautier-suply@cellnovo.com

Support: The publication of this article was supported by Cellnovo

$\mathrm{Ltd}$. The views and opinions expressed in the article are those of

the authors and not necessarily those of Cellnovo Ltd.
An effective basal-bolus regimen is the gold standard in type 1 diabetes mellitus (T1DM) management as it most closely resembles physiological beta-cell pancreatic insulin secretion. Multiple daily injections (MDI) are commonly used to deliver insulin; however, where these fail to manage glycated haemoglobin (HbA1C) within defined parameters, continuous subcutaneous insulin infusion (CSII, also known as pump therapy) is the recommended alternative. ${ }^{1-3}$ Clinical evidence from several metaanalyses of randomised, controlled trials of glycaemic control with MDI compared with CSII have showed a significant improvement in mean HbA1c levels with insulin pump therapy. ${ }^{4-6}$ In addition, the improvement was greater for patients with higher initial $\mathrm{HbA} 1 \mathrm{C} .{ }^{6,7}$ Where meta-analysis studies have not demonstrated a reduction in hypoglycaemic events ${ }^{8,9}$ the reduction in the number of severe hypoglycaemic events demonstrated a benefit in the insulin pump therapy group compared with MDI. ${ }^{6}$

The main advantage of CSII is the flexibility of the basal insulin response to glycaemic variability compared with a basal insulin injection. The basal rate delivered with the pump can be adapted to varying need during the day based on features of the pump such as a bolus calculator, 10,11 activity tracking and food library. ${ }^{12}$ The threshold-suspend ${ }^{13,14}$ and continuous glucose monitoring features automatically stop the pump when pre-set parameters are reached, thereby lowering the risk of hypoglycaemia. Consequently, the glycaemic profile can be adapted to mitigate glycaemic outcomes such as nocturnal hypoglycaemia or the 'dawn phenomenon' ${ }^{2},{ }^{215}$ Patch pumps have demonstrated the same glycaemic control as tethered pumps, ${ }^{16,17}$ coupled with an improvement in quality of life and patient satisfaction. ${ }^{18,19}$

The Cellnovo Diabetes Management System (Cellnovo, Bridgend, UK) is the world's first mobile diabetes management system, comprising a patch pump for accurate insulin delivery, ${ }_{10}^{20}$ an activity monitor, a mobileenabled wireless touch-screen handset with integrated blood glucose 
Table 1: Baseline clinical characteristics of the full cohort (mean \pm standard deviation)

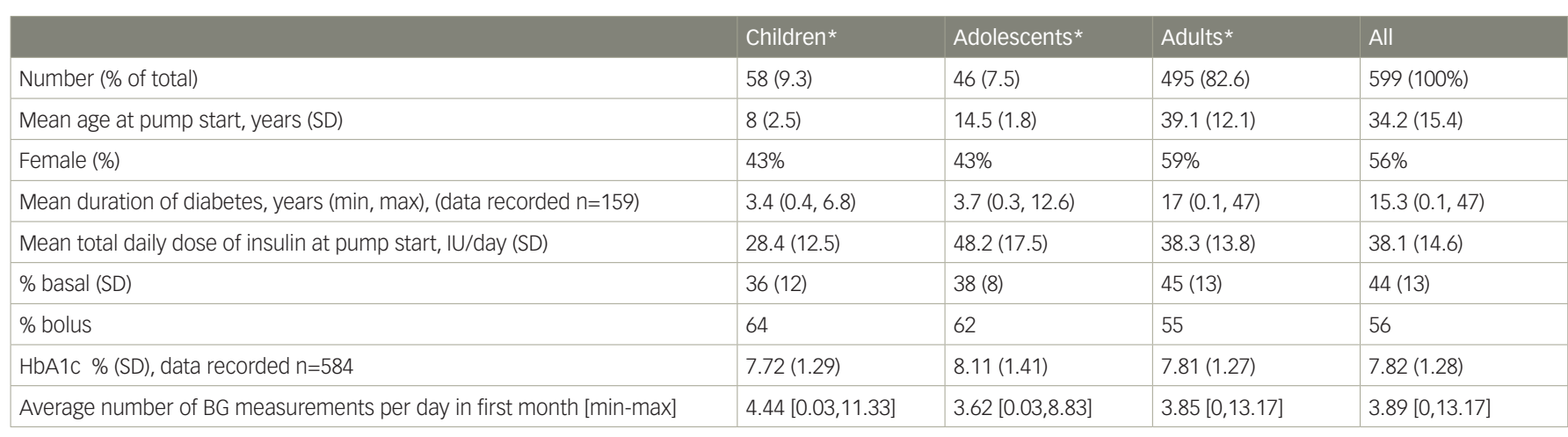

*Children 0-12 years, adolescents 12-18 years, adults $>18$ years.

$B G=$ blood glucose; $H$ HA1C = glycated haemoglobin; $\max =$ maximum; $\min =$ minimum; $S D=$ standard deviation .

(BG) meter and automatic connectivity to secure servers. ${ }^{12}$ The system's unique features and advantages have been outlined previously. ${ }^{12}$ Users of the Cellnovo System receive a personal login to the secure mobile diabetes management portal where they can access automatically collected data in order to review their treatment regimen and determine if adjustments are required. The patient's healthcare professional (HCP) can access data pertaining to their latest recorded blood sugar, average blood sugar, insulin dosing, hypoglycaemia frequency and blood testing routine, facilitating early intervention where necessary. Working in conjunction with the patient, data can be also analysed to identify trends, patterns and glycaemic status; this interactivity using real-time data can facilitate greater patient self-management and allow clinic visits to be focused on current and accurate information. ${ }^{12}$

\section{Retrospective data study}

Having real-time data from patients using the Cellnovo pump during their everyday life presents an opportunity to gain a deep understanding of their clinical status on a daily basis and over time. The primary aims of this retrospective data study therefore were:

- To review and present clinical and demographic characteristics of the entire cohort enrolled in the Cellnovo database and establish a profile of patients at their first month of pump use. This will enable clinicians to compare these characteristics with those in their own daily clinical practice at pump initiation.

- To analyse a number of glycaemic parameters from a sub-cohort of pump users.

\section{Methods}

\section{Data collection}

Prior to starting on the Cellnovo pump, patients provided written informed consent to the anonymous collection, storage and use of their demographic and clinical data in the Cellnovo Diabetes Management System. This baseline data are recorded when the patient starts pump therapy; thereafter, BG measurements and hourly basal and bolus doses delivered are recorded.

\section{Full cohort}

Data were retrieved from January 2013 to September 2017; the baseline demographic and clinical data of the 599 patients (worldwide) reviewed included:
- age, gender

- total daily dose (TDD), ratio of daily basal and bolus to the TDD in the first month of pump use;

- duration of T1DM where available;

- HbA1C; and

- the number of BG measurements per day in the first month of pump use.

\section{Sub-cohort}

From this data set, we retrieved a smaller cohort of 166 patients who had used the pump for at least 6 months and had recorded their BG at least three times a day on average; this was to ensure a sufficient duration of pump use and enough glycaemic data to undertake analysis. In this subcohort, we analysed:

- mean HbA1c;

- mean BG and standard deviation (SD) to express variability;

- number of hypoglycaemic events per week, comparing first and last analysed month of data; and

- the median follow-up time for this cohort of 1 year (range 6-41 months).

\section{Statistical analysis}

Data were tested for normality using the Shapiro-Wilk test. The paired Student's t-test and Wilcoxon rank-sum test were used as they were appropriate to identify changes in mean and SD of BG measurements. A $p$ value of less than 0.05 was taken to indicate significance.

\section{Results}

\section{Full cohort}

Data were retrieved from January 2013 to September 2017. Table 1 shows the baseline demographic and clinical characteristics of the full cohort of patients ( $n=599), 495$ (82.6\%) of whom were adults. The mean age at start of pump therapy was 8 years in children, 14.5 years in adolescents and 39.1 years in adults.

\section{Insulin total daily dose}

From baseline to month 1, mean TDD of insulin in the first month was $38.1 \pm 14.6 \mathrm{IU} /$ day; the TDD was lowest in children $(28.4 \pm 12.5 \mathrm{IU} /$ day), and highest in adolescents ( $48.2 \pm 17.5 \mathrm{IU} /$ day). The bolus doses as a fraction of the TDD were highest in children (64\%) and lowest in adults (55\%). 
Table 2: Distribution of HbA1c in full cohort at pump initiation

\begin{tabular}{|l|l|l|l|l|}
\hline Age group (n) & $\begin{array}{l}\text { Percent of } \\
\text { patients with } \\
\text { HbA1C }<7 \%\end{array}$ & $\begin{array}{l}\text { Percent of } \\
\text { patients with } \\
\text { HbA1C 7-8\% }\end{array}$ & $\begin{array}{l}\text { Percent of } \\
\text { patients with } \\
\text { HbA1C 8-9\% }\end{array}$ & $\begin{array}{l}\text { Percent of } \\
\text { patients with } \\
\text { HbA1C >9\% }\end{array}$ \\
\hline Children (57) & 18 & 49 & 23 & 10 \\
\hline Adolescents (44) & 14 & 32 & 29 & 25 \\
\hline Adults (483) & 19 & 41 & 25 & 15 \\
\hline
\end{tabular}

HbA1C = glycated haemoglobin.

Table 3: Distribution of HbA1c in sub-cohort at pump initiation

\begin{tabular}{|l|l|l|l|l|}
\hline Age group* $(n)$ & $\begin{array}{l}\text { Percent of } \\
\text { patients with } \\
\text { HbA1C }<7 \%\end{array}$ & $\begin{array}{l}\text { Percent of } \\
\text { patients with } \\
\text { HbA1C 7-8\% }\end{array}$ & $\begin{array}{l}\text { Percent of } \\
\text { patients with }\end{array}$ & $\begin{array}{l}\text { Percent of } \\
\text { patients with }\end{array}$ \\
\hline Children (15) & 7 & 60 & 20 & 13 \\
\hline Hdolescents (6) & 17 & 66 & 17 & 0 \\
\hline Adults (130) & 15 & 48 & 25 & 12 \\
\hline
\end{tabular}

*Some data values missing from system. HbA1C = glycated haemog/obin.

\section{Blood glucose measurements}

From baseline to month 1, mean number of BG measurements in children, adolescents and adults was 4.40, 3.62 and 3.85 per day respectively in the first month.

\section{HbA1c level at baseline}

The mean $\mathrm{HbA} 1 \mathrm{C}$ at baseline (Table 1) was $7.72 \%$ in children, $8.11 \%$ in adolescents and $7.81 \%$ in adults. Table 2 shows HbA1C readings by age group. Of the 599 patients, data were available for 584 patients (57 children, 44 adolescents and 483 adults). The percentage of patients in the children and adult age groups with an HbA1c below $7 \%$ was largely similar (18\% and 19\%, respectively), whereas just over half (54\%) of the adolescents had an HbA1c above 8\% at pump initiation.

\section{Sub-cohort}

In total, 166 patients were included in the sub-cohort (16 children, 7 adolescents and 143 adults). Due to small numbers, neither HbA1C (children and adolescent group) nor mean BG and SD (adolescent group) were analysed.

\section{HbA1c level}

Table 3 shows baseline HbA1c values as percentages (range $<7->9 \%$ ). Of the 166 patients in the sub-cohort, HbA1c data were recorded for 151 patients ( 15 children, 6 adolescents and 130 adults). Overall, 34 patients (20.5\%) had two HbA1C measurements more than 90 days apart (mean follow-up time 10 months, range 3.5-25.7 months); of these, 30 were adults. In this adult group there was a significant reduction in $\mathrm{HbA} 1 \mathrm{C}$ of $0.54 \%$ ( $p=0.002$; Table 4).

Figure 1 shows the improvement in $\mathrm{HbA} 1 \mathrm{C}$ values as a function of the initial value measured at baseline. A correlation analysis was carried out between initial HbA1C and improvement. Pearson's correlation coefficient was calculated to be $r=0.58, p=0.0007$ (28 degrees of freedom), confirming an increased improvement in $\mathrm{HbA} 1 \mathrm{C}$ levels with higher HbA1C levels at pump initiation.

\section{Hypoglycaemic events}

Table 4 shows the changes in $\mathrm{HbA} 1 \mathrm{c}$, number of hypoglycaemic events per week and mean BG from baseline to last month of data capture for the sub-cohort. In the children's group $(n=16)$, there is some decrease in the number of hypoglycaemic events per week between the first and last month of data collection: 3.7 hypoglycaemic events on average per week in the first month of use, and 3.0 in the last month, with 11 (68.75\%) children having fewer hypoglycaemia events. This decrease is not statistically significant. In the adolescent group, hypoglycaemic events decreased almost significantly from 3.8 to 2.3 a week $(p=0.05)$. In adults $(n=143)$, there was a significant decrease in the number of hypoglycaemic events, by one event less per week $(p<0.00001)$. In the first month of pump use there were on average 3.4 hypoglycaemic events, whereas by the last month this had fallen to 2.4 per week, with 93 (65.03\%) having fewer events.

\section{Mean blood glucose level}

In the adult group, there was a small but significant increase in mean BG level ( $p=0.01)$. Of 143 adults, 21 (14.6\%) had a significant improvement of between $13.4 \mathrm{mg} / \mathrm{dl}$ and $158.1 \mathrm{mg} / \mathrm{dl}$. Furthermore, 42 (29.6\%) had a significant increase in the BG levels of between $7.9 \mathrm{mg} / \mathrm{dl}$ and $83.3 \mathrm{mg} / \mathrm{dl}$.

\section{Blood glucose variability (measured by standard deviation)}

There was no significant change in variability between the first and last month in the children's group. Five (31\%) had a decrease of variability between $1.7 \mathrm{mg} / \mathrm{dl}$ and $37.5 \mathrm{mg} / \mathrm{dl}$, while 11 (69\%) had an increase of variability between $3.7 \mathrm{mg} / \mathrm{dl}$ and $21.1 \mathrm{mg} / \mathrm{dl}$. In the adult group, there was a small, significant increase in BG variability $(p=0.007)$ of $3.45 \pm 15.2$ $\mathrm{mg} / \mathrm{dl}$. Overall, 53 (37\%) had a decrease of variability between $0.4 \mathrm{mg} / \mathrm{dl}$ and $51.6 \mathrm{mg} / \mathrm{dl}$, whereas 90 (63\%) had an increase of variability between $0.3 \mathrm{mg} / \mathrm{dl}$ and $53.6 \mathrm{mg} / \mathrm{dl}$.

\section{Discussion}

The Cellnovo Online platform is not a registry, but the data available provide clinical and lifestyle information about the patient's daily life. This review describes the profile of patients in multiple sites who are registered on the Cellnovo Diabetes Management System.

Results from the median follow-up of 1 year in the sub-cohort show a significant improvement in $\mathrm{HbA} 1 \mathrm{C}$ and a downward trend in children, and a decrease in hypoglycaemia frequency of approximately one event per week in adolescents and adults. Mean BG levels have remained the same for children and adolescents with a very slight increase on average for adults. While BG variability has not decreased, this analysis has to be interpreted carefully as it is real-life retrospective data. BG measurements can be biased; for example, if a patient is feeling unwell, they may measure BG more frequently, whereas when they feel well, they may reduce the number of measurements they undertake. Encouragingly, however, mean BG improved by $14.6 \%$ of adult pump users.

Retrospective results from two studies of the Omnipod ${ }^{\circledR}$ System (Insulet Corporation, Billerica, MA, US) found both similarities and differences when compared with the data reported here. For example, in our cohort $7.46 \%$ of patients were aged under 18 years at pump initiation, whereas the Austrian and German Diabetes-patient-documentation (DPV) registry showed a larger proportion of children ( $74 \%$ aged $<20$ years)..$^{21}$ An American study showed just over one-third of patients were aged under 18 years, with a mean age of 29 years. ${ }^{17}$ The differences between these studies and ours may be explained by differences in criteria for pump prescription between countries and the growing number of children using pump therapy, particularly in the US. ${ }^{22}$

The mean duration of diabetes in the adult group in the present study was the same as the American study, with slight differences among 
Table 4: Clinical parameters from baseline to final month of data analysis in the sub-cohort (mean \pm standard deviation)

\begin{tabular}{|c|c|c|c|c|c|c|c|c|c|}
\hline & \multicolumn{3}{|l|}{ Children $(n=16)$} & \multicolumn{3}{|c|}{ Adolescents $(n=7)$} & \multicolumn{3}{|l|}{ Adults $\left(n=143^{*}\right)$} \\
\hline & $\begin{array}{l}\text { Baseline to and } \\
\text { of first month }\end{array}$ & Last month & $\mathrm{p}$ value & $\begin{array}{l}\text { Baseline to end } \\
\text { of first month }\end{array}$ & Last month & $p$ value & $\begin{array}{l}\text { Baseline to end } \\
\text { of first month }\end{array}$ & Last month & $\mathrm{p}$ value \\
\hline HbA1c (\%) (adults n=30) & NA & NA & NA & NA & NA & NA & $7.67 \pm 0.98$ & $7.13 \pm 0.85$ & 0.002 \\
\hline $\begin{array}{l}\text { Number hypoglycaemic } \\
\text { events per week }\end{array}$ & $3.7 \pm 1.9$ & $3.0 \pm 2.2$ & 0.27 & $3.8 \pm 2.6$ & $2.3 \pm 2.0$ & 0.05 & $3.4 \pm 2.5$ & $2.4 \pm 2.0$ & $<0.00001$ \\
\hline $\mathrm{BG}(\mathrm{mg} / \mathrm{dl})$ & $178.0 \pm 23.6$ & $182.6 \pm 32.7$ & 0.55 & $159.7 \pm 32.3$ & $166.0 \pm 36.3$ & 0.46 & $162.7 \pm 30.3$ & $169.0 \pm 30.0$ & 0.01 \\
\hline $\begin{array}{l}\text { Standard deviation of BG } \\
(\mathrm{mg} / \mathrm{dl})\end{array}$ & $83.0 \pm 19.0$ & $86.0 \pm 13.6$ & 0.4 & $75.6 \pm 8.0$ & $75.0 \pm 24.0$ & 0.9 & $72.6 \pm 16.0$ & $76.0 \pm 17.0$ & 0.007 \\
\hline
\end{tabular}

*Some data values missing from system. BG = blood glucose; HbA1C = glycated haemoglobin; $N A$ = not applicable.

adolescents and children. In the DPV registry, 57\% of patients had diabetes for less than 5 years due to the higher proportion of children and adolescents using the pump.

In this review, the TDD of insulin at baseline for adults was low (38 IU/day), almost the same as that of the DPV registry (20-30 age group: 39 IU/day; $>40$ years: $35 \mathrm{IU} /$ day), whereas the American study showed a greater TDD of insulin among adults, at 59 IU/day (adolescents: 52 IU/day; children <13 years: 25 IU/day).

When comparing the HbA1c trends in our study, similar results to those of Layne et al. are seen; ${ }^{17}$ a decrease in hypoglycaemia frequency by one event per week 3 months after initiation of pump therapy. Other studies have used retrospective data to evaluate the use of pump therapy on clinical parameters such as reduction in HbA1C and on the frequency of hypoglycaemic episodes..$^{23} \mathrm{~A}$ recent study ${ }^{16}$ compared the efficacy of different models of pumps among different manufacturers (Medtronic, Minimed Inc. [Northridge, CA, US], Roche Diabetes Care [Burgdorf, Switzerland], Animas Corporation [West Chester, PA, US], Omnipod [Insulet Corporation, Billerica, MA, US]) with respect to $\mathrm{HbA} 1 \mathrm{C}$, and found that while there was no significant difference between pumps at 1 year after pump start, the overall decrease in HbA1C was no more than our result of $0.5 \%$ (reduction from 8.7 to $8.2 \%$ ). ${ }^{16}$ Johnson et al. reviewed data pertaining to 345 children (aged $<18$ years) on the Western Australian Childhood Diabetes Database (WACDD) over a 7-year period and found that the mean $\mathrm{HbA} 1 \mathrm{C}$ reduction was $0.6 \%$, which remained significant throughout the 7 years of follow up. ${ }^{24}$ Severe hypoglycaemia reduced from 14.7 to 7.2 events per 100 patient-years $(p<0.001)$. In another 7-year follow-up study, Mameli et al. showed an improvement in $\mathrm{HbA} 1 \mathrm{C}$ of $0.5 \%$ at year 1 , and further improvement at year 7 , with a significant decrease in severe hypoglycaemia of 0.5 to $0.9 \% .{ }^{25}$ Sherr et al. explored metabolic control in young people, using data from three diabetes registries; the Austrian and German DPV $(n=26,198)$, T1D Exchange (T1DX; $n=13,755)$ and the National Paediatric Diabetes Audit (NPDA; $n=14,457) .{ }^{26}$ Pooled analysis of the data showed that pump use was associated with a lower mean HbA1c (pump: $8.0 \pm 1.2 \%$ [64 $\pm 13.3 \mathrm{mmol} / \mathrm{mol}]$ versus MDI: $8.5 \pm 1.7 \%$ $[69 \pm 18.7 \mathrm{mmol} / \mathrm{mol}], \mathrm{p}<0.001)$.

In respect of hypoglycaemic events, Plotnick et al. demonstrated a reduction in number of events after pump therapy start (12 versus 17 events per 1,000 patients per month, rate ratio: $0.46,95 \%$ confidence interval: 0.21-1.01). ${ }^{27}$ Johnson et al. also demonstrated that the number
Figure 1: HbA1C improvement in the full cohort (baseline to month 1)

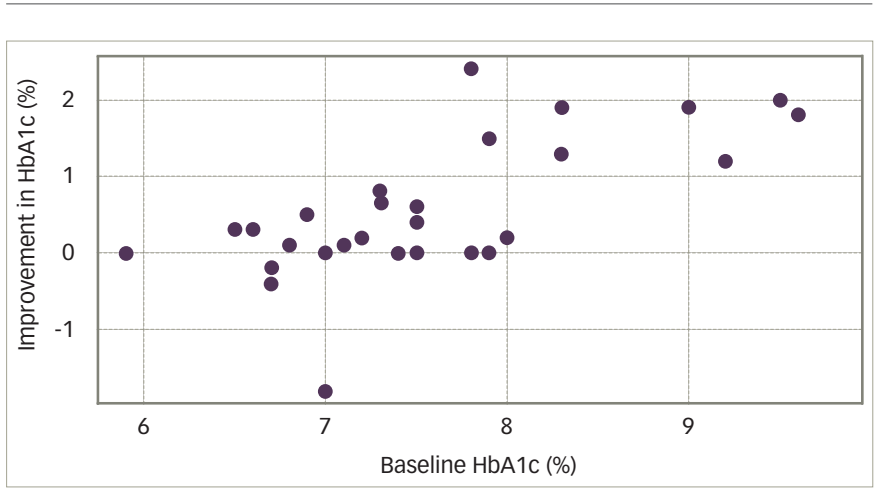

$H B A 1 C=$ glycated haemoglobin.

of events dropped by $50 \%$ to that experienced in the year before pump therapy (14.7 to 7.2 events per 100 patient-years; $p<0.001) .^{24}$

\section{Limitations}

It is acknowledged that the primary aim of the database is to help patients and HCPs manage insulin dose adaptation in real-time with respect to different daily life situations, rather than to study the glycaemic effect of the system. While real-time data are recorded automatically by the system, BG measurements are entered by the patient, so may be biased towards those times when the patient feels unwell. This may explain the lack of improvement in either mean $\mathrm{BG}$ or $\mathrm{BG}$ variability. In addition, as this is a retrospective review of data, it is not possible to explore anomalies in data, or to discern the confounding variables.

\section{Conclusion}

The results from real-life data showed a significant and meaningful improvement in $\mathrm{HbA} 1 \mathrm{C}$ - a decrease of $0.54 \%$ - and hypoglycaemia frequency at 1 year follow-up. Mean BG levels remained the same for children and adolescents with a very slight increase on average for adults, and while BG variability has not decreased, this is real-life retrospective data.

Further studies are needed to evaluate all the benefits of the system. To this end, for clinical and regulatory purposes, we plan to undertake prospective studies to assess glycaemic control and outcomes, as well as evaluating quality of life and patient feedback in clinical situations with the involvement of HCPS. $\square$ 


\section{Review Diabetes}

1. Grunberger G, Abelseth JM, Bailey TS, et al. Consensus statement by the American Association of Clinical Endocrinologists/American College of Endocrinology Endocrinologists/American College of Endocrinology Insulin Pump Management Task Force. Endocrine Practice.

2014;20:463-89.

National Institute for Health and Clinical Excellence [NICE]. Technology appraisal 151. Continuous subcutaneous insul infusion for the treatment of diabetes mellitus, 2008. Available at: www.nice.org.uk/guidance/ta151 (accessed 23 January 2018)

3. Heinemann L, Fleming GA, Petrie JR, et al. Insulin pump risks and benefits: a clinical appraisal of pump safety standards, adverse event reporting, and research needs a joint statement of the European Association for the Study of Diabetes and the American Diabetes Association Diabetes Technology Working Group. Diabetes Care. 2015;38:716-22.

4. Misso ML, Egberts KJ, Page M, et al. Continuous subcutaneous insulin infusion (CSII) versus multiple insulin injections for type 1 diabetes mellitus. Cochrane Database Syst Rev. 2010;1:CD005103.

5. Pickup JC, Mattock MB, Kerry S, Glycaemic control with continuous subcutaneous insulin infusion compared to intensive insulin injection therapy in type 1 diabetes: metaanalysis of randomised controlled trials. BMJ. 2002;324:705-8.

6. Pickup JC, Sutton AJ. Severe hypoglycaemia and glycaemi control in type 1 diabetes: meta-analysis of multiple daily insulin injections versus continuous sub- cutaneous insulin infusion. Diabet Med. 2008;25:765-74.

7. Retnakaran R, Hochman J, DeVries JH, et al. Continuous subcutaneous insulin infusion versus multiple daily injections:
the impact of baseline A1c. Diabetes Care. 2004;27:2590-6.

8. Benkhadra K, Alahdab F, Tamhane SU, et al. Continuous subcutaneous insulin infusion versus multiple daily injections in individuals with type 1 diabetes: a systematic review and meta-analysis. Endocrine. 2016;55:77-84

9. Fatourechi M, Kudva YC, Murad MH, et al. Hypoglycemia with intensive insulin therapy: a systematic review and metaanalyses of randomized trials of continuous subcutaneous insulin infusion versus multiple daily injections. I Clin Endocrinol Metab. 2009:94:729-40.

10. Zisser $H$, Wagner R, Pleus $S$, et al. Clinical performance of three bolus calculators in subjects with type 1 diabetes mellitus: head-to-head-to-head comparison. Diabetes Technol Ther. 2010;12:955-61

11. Boizel R, Pinget M, Lachgar K, et al. Clinical evaluation of the use of a multifunctional remotely controlled insulin pump: multicenter observational study. J Diabetes Sci Technol. 2014:8:1145-50.

12. Bain S. The Cellnovo Insulin Delivery System. European Endocrinol. 2017:13:13-6.

13. Bergenstal RM, Klonoff DC, Garg SK, et al. Threshold-based insulin-pump interruption for reduction of hypoglycemia. N Eng/ J Med. 2013:369:224-32.

14. Riemsma R, Corro Ramos I, Birnie R, et al. Integrated sensoraugmented pump therapy systems [the MiniMed $^{\circledast}$ Paradigm $^{\text {TM }}$ Veo system and the Vibe ${ }^{\mathrm{TM}}$ and G4® PLATINUM CGM (continuous glucose monitoring) system] for managing (continuous glucose monitoring) system] for managing
blood glucose levels in type 1 diabetes: a systematic blood glucose levels in type 1 diabetes: a systematic review and econor

15. Nicolajsen T, Samuelsson A, Hanas R. Insulin doses before and one year after pump start: children have a reversed dawn phenomenon. J Diabetes Sci Technol. 2012;6:589-94.

16. Leelarathna L, Roberts SA, Hindle A, et al. Comparison of different insulin pump makes under routine care conditions in adults with type 1 diabetes. Diabet Med. 2017;34:1372-9.

17. Layne J, Parkin CG, Zisser H. Efficacy of the Omnipod Insulin Management System on glycemic control in patients with type
1 diabetes previously treated with multiple daily injections or continuous subcutaneous insulin infusion. J Diabetes SC Technol. 2016:10:1130-5.

18. Polonsky WH, Hessler D, Layne JE, Zisser H. Impact of the Omnipod Insulin survey of currentusers. Diabetes Technol quer. 2016, 18:664-70.

19. Kelly P. Achieving effective glycaemic control using an insulin micro-pump. Br J Community Nurs. 2017;22:66-76.

20. Bowen J, Allender C. A Comparative pulse accuracy study of two commercially available patch insulin infusion pumps. European Endocrinol. 2016;12:79-84.

21. Danne T. Clinical outcomes from the German/Austrian DPV Registry. Presented at: The European Association for the Study of Diabetes (EASD) Conference, Paris, France, 11-15 September 2017.

22. Pickup J. Insulin pumps. Int I Clin Pract. 2011;64:16-9.

23. Pickup J. Insulin-pump therapy for type 1 diabetes mellitus. N Eng/ J Med. 2012;366:1616-24.

24. Johnson S, Cooper MN, Jones TW, Davis EA. Long-term outcome of insulin pump therapy in children with type 1 diabetes assessed in a large population-based case-control study. Diabetologia. 2013;56:2392-400

25. Mameli C, Scaramuzza AE, Ho J, et al. A 7-year follow-up retrospective, international, multicenter study of insulin pump therapy in children and adolescents with type 1 diabetes. Acta Diabetologica. 2013;51:205-10

26. Sherr JL, Hermann JM, Campbell F, et al. Use of insulin pump therapy in children and adolescents with type 1 diabetes and its impact on metabolic control: comparison of results from three large, transatlantic paediatric registries. Diabetologia. 2016;59:87-91

27. Plotnick L, Clark LM, Brancati FL, Erlinger T. Safety and effectiveness of insulin pump therapy in children and adolescents with type 1 diabetes. Diabetes Care. 2003:26:1142-6. 